\title{
An Experimental Investigation on the Generation of a Stable Arch in Granular Materials Using a Developed Trapdoor Apparatus
}

\author{
Ali Ahmadi ${ }^{1}$ and Ehsan Seyedi Hosseininia*1 \\ ${ }^{1}$ Civil Engineering Department, Faculty of Engineering, Ferdowsi University of Mashhad, Mashhad, Iran
}

\begin{abstract}
This paper discusses the formation of stable arches in granular materials by using a series of laboratory tests. To this aim, a developed trapdoor apparatus is designed to find dimensions of arches formed over the door in cohesionless aggregates. This setup has two new important applications. In order to investigate the maximum width of the opening generated exactly on the verge of failure, the door can be open to an arbitrary size. In addition, the box containing granular materials (or base angle) is able to be set on optional angles from zero to 90 degrees with respect to the horizontal. Therefore, it is possible to understand the effect of different levels of gravity accelerations on the formed arches. It is observed that for all tested granular materials, increasing the door size and decreasing the base angle, both cause to increase the width and height of the arch. Moreover, the shape of all arches is governed by a parabola. Furthermore, the maximum door width is approximately five to 8.6 times the particle size, depending on the internal friction angle of materials and the base angle.
\end{abstract}

\section{Introduction}

Arching is one of the most common phenomena encountered in granular materials both in the field and laboratory. Terzaghi [1] defined arching effect as the transfer of pressure from a yielding mass of soil onto adjoining stationary parts. In other words, arching is closely related to the mobilization of shear strength induced by the relative movement in materials. He used trapdoor tests to explain how stress is transferred from yielding parts of a soil mass to adjacent stationary, nonyielding parts that led to the formation of an arching zone.

By using this idea, several works have been carried out to investigate the arching effect as load transferring in different engineering problems, including earth pressure on retaining structures [2], stability of tunnels [3-7], bearing resistance of piles [8], settlement of pile supported embankments [9], load on buried structures [10], and granular flow in hoppers and silos [11-14]. A literature study on the arching effect can be found in Tien [15]. More recently, the numerical Discrete Element Method has been used to explore the application of arching in soil $[16,17]$. Approximate theories have been developed for the analysis of granular flow and the design of hoppers [18-20]. Guo and Zhou [19] have studied the formation of critical stable arch over an opening by using trapdoor test. In their tests, the trapdoor width was fixed. Motivated by the aforementioned literature review, this study tries to study the conditions of the formation of stable arches over an opening before the critical (last stable) arch is formed. In this study, the maximum size of opening door related to critical width and height of the arch over the door is explored by considering various gravity acceleration (from zero to $90^{\circ}$ base angle of materials box). In the former study (Gou and Zhou's setup), the base angle was fixed at $30^{\circ}$. This developed setup can help designers to select a size of hopper or silo outlet with various base angle of materials.

\section{Experimental tests}

\subsection{Developed trapdoor test}

The trapdoor apparatus can be used in order to investigate the formation of arch in granular materials. In the apparatus introduced by Guo and Zhou [19], the base has an angle of 30 degrees to the horizontal. The apparatus is developed in this study as explained as follows. Fig. 1 shows this setup. The apparatus has a box, which can set on arbitrary angle from zero to 90 degrees with respect to the horizontal, so as to apply different gravity accelerations ( $g$ ) over materials. The box is considered as a space between MDF base plate, lateral frames (called shoulders) and a plexiglass inserted in the fissure existing on the lateral frames. The box is fixed on the base with dimension of $30 \times 40 \mathrm{~cm}$. A plexiglass layer can be placed over the box with a distance of average grains diameter plus 1-2 mm such

\footnotetext{
* Corresponding author: eseyedi@um.ac.ir
} 
that only one layer of particles in the box can be held. Thus, particles move down without any friction with plexiglass and negligible friction with base plate. The particles are stacked only in single layer such that it simulates the plane strain condition. Two transitive segments (called trapdoor blocks), are contrived at the lowest level of materials to access different door width and also use as a stopper for granular materials.
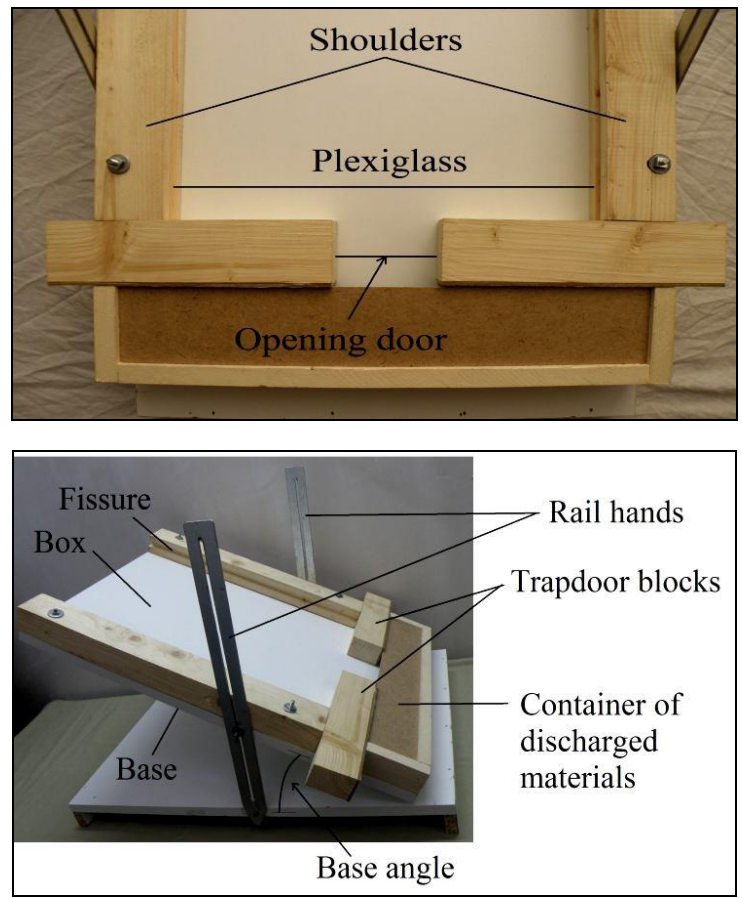

Fig. 1. Developed trapdoor apparatus

\subsection{Selected granular materials}

Two kinds of granular materials were used in this study, including gravel packing with the average size of $9 \mathrm{~mm}$ and plastic spherical beads with the diameter of $12 \mathrm{~mm}$ in two density conditions (i.e. loose and dense). The gradation curves of these materials are shown in Fig. 2.

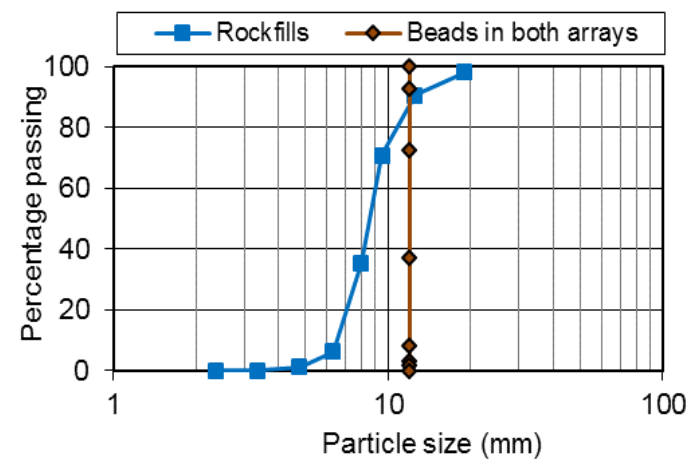

Fig. 2. Gradation curve of granular materials (Gravel: d50 9mm, Beads: d50 $12 \mathrm{~mm}$ )

The granular materials used in the tests are presented in Fig. 3. In order to access loose and dense packing of beads, two arrays of bead particles are considered: square arrangement as loose state (Fig. 3a) and hexagonal arrangement as dense state (Fig. 3b). The array for gravel is shown in Fig. 3(c). The density of tested materials that were used in the box tests were calculated as $1.58 \mathrm{~g} / \mathrm{cm}^{3}$ for gravel packing and for glass beads as $1.05 \mathrm{~g} / \mathrm{cm}^{3}$ for dense and $0.96 \mathrm{~g} / \mathrm{cm}^{3}$ for loose arrays. The internal friction angles of tested materials were measured by finding the angle of repose $(\varphi)$. Values of $\varphi$ are $23^{\circ}, 37^{\circ}$ and $45^{\circ}$ for loose beads, dense beads and gravel, respectively.

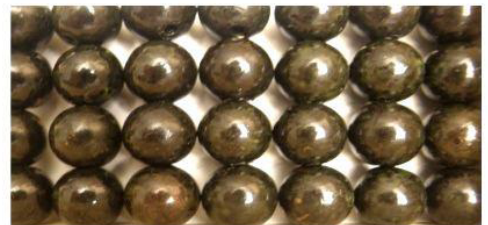

(a) Beads in loose array

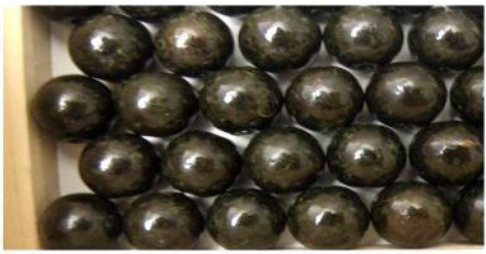

(b) Beads in dense array

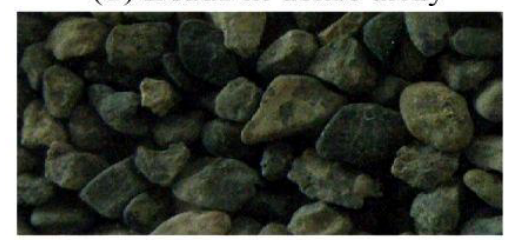

(c) Rockfills

Fig. 3. Tested granular materials

\subsection{Test performance}

First, the box is fixed on desired angle, then two trapdoor blocks move away and a distance is created between them. A stiff rectangular rubber as the door fills this space. In second step, granular materials come in the box. It must be considered that entering the materials in the box can be achieved by various manners. For example, gravel is inserted in the box after fixing plexiglass, but beads are first put in loose or dense array in the existing space between segments, shoulders and base plate, then plexiglass is placed in fissures. This method facilitates the process of arranging bead grains as loose or dense array. Finally, rubber door moves down and granular materials discharge and fall into the container. The whole materials do not discharge, but a stable arch forms over the door after a short time. This arch can carry static pressure of upper materials and transfers it to its two bottom supports by arching application. In every run of the test, the distance between two blocks, i.e., opening door width (W) increases $2 \mathrm{~mm}$ as compared with previous stage, then the width and height size of the arch corresponding to door width are recorded in sheets relating to specific angle. This process is repeated so that no stable arch forms anymore. On the verge of arch collapse, i.e., no arch can be generated, maximum door width $\left(\mathrm{W}_{\max }\right)$ and the critical arch width and height were measured in this study. It is here noted that the arch width, which is defined as the internal distance between two piers of the arch, might be different from the trapdoor width. This subject is mentioned in the next section. Each test has been 
repeated at least three times to examine the repeatability of the experiment. The experimental results presented in this study correspond to the assured and repeatable observations.

\section{Experimental observations}

By performing experimental tests on four base angles $(\theta)$ consisting $10^{\circ}, 40^{\circ}, 70^{\circ}$, and $90^{\circ}$, considerable results were observed. Fig. 4 shows photographs of typical formed arches.

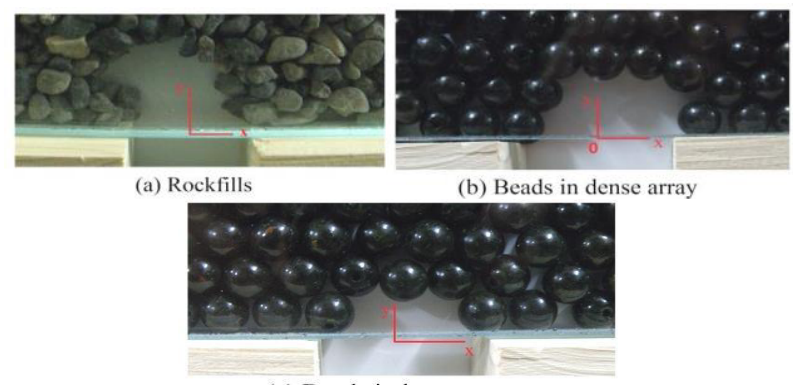

(c) Beads in loose array

Fig. 4. Typical photographs of arching over door width $\mathrm{W}=5.6$ $\mathrm{cm}$

Arching effect makes a stable arch in ach granular medium. Fig. 5 presents the loci of each particle in stable arch formed over door widths (W) of $2.8 \mathrm{~cm}$ and $5.6 \mathrm{~cm}$ and base angles of $40^{\circ}$ and $90^{\circ}$. Note that $\mathrm{x}$ and $\mathrm{y}$ values represent the loci of the particles that forms an arch. As shown for all the materials, the arch width is smaller than door width. The arch height is greater for dense array $\left(\varphi=37^{\circ}\right)$ compared to loose array $\left(\varphi=23^{\circ}\right)$, although the diameter of bead grains is equal in both arrays (with $\mathrm{d}=12 \mathrm{~mm}$ ). Meanwhile, the arch dimensions of gravel $\left(\mathrm{d} 50=9 \mathrm{~mm}, \varphi=45^{\circ}\right)$ is approximately greater than dense beads. This indicates that the internal friction angle of materials has mobilized the shear strength between particles and it is the most important factor in arch formation for granular materials. Increasing the opening door width causes to discharge more materials and to decrease the surcharge.

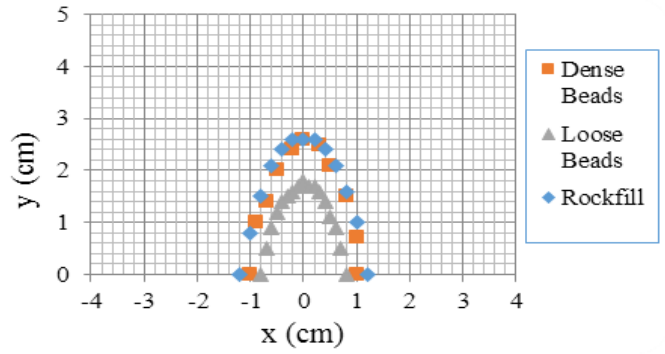

(a) $\theta=40^{\circ}, \mathrm{W}=2.8 \mathrm{~cm}$

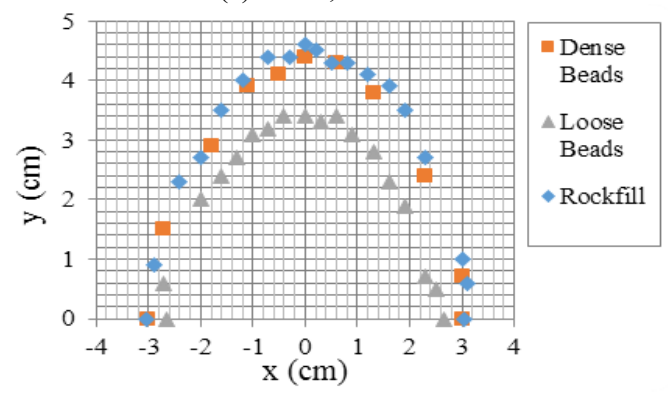

(b) $\theta=40^{\circ}, W=5.6 \mathrm{~cm}$

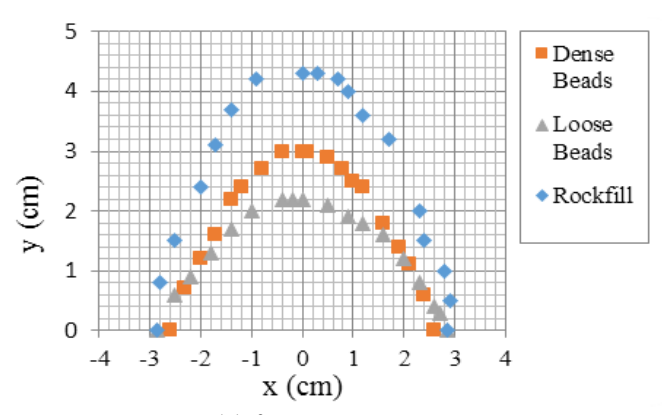

(c) $\theta=90^{\circ}, W=5.6 \mathrm{~cm}$

Fig. 5. Comparison between arch shapes formed on determined base angle and door width

In Fig. 6, the variation of the arch height $(\mathrm{H})$ versus the door width (W) is presented. As seen, the arch height increases as the door width increases. This might be as a result of the reduction in surcharge on the arch that causes the arch to endure less pressure and consequently to have greater height. However, the arch height $(\mathrm{H})$ is reduced as the base angle $(\theta)$ is increased. The more the base angle inclines, the more effective gravity acceleration $(g \times \sin \theta)$ exerts on granular materials. This increases the effective surcharge on the arch and shortens its height since the arch supports more loads in this condition. This observation has been also shown by numerical simulations $[21,22]$. It is also observed that as the door width increases, more materials are discharged and consequently the arch width is greater, until no stable arch can form. The arch forming on the verge of collapse is called as "critical arch". For this arch, the width of door and the arch possess maximum possible size. On the contrary, the height of the arch is not the maximum, but it decreases slightly. The reason might be because the arch cannot endure the materials that have tendency to discharge, and for adoption of this condition, the arch should decrease its height.

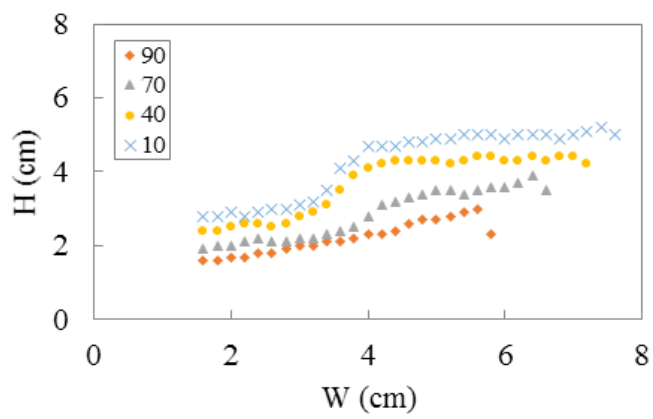

(a) Beads in dense array

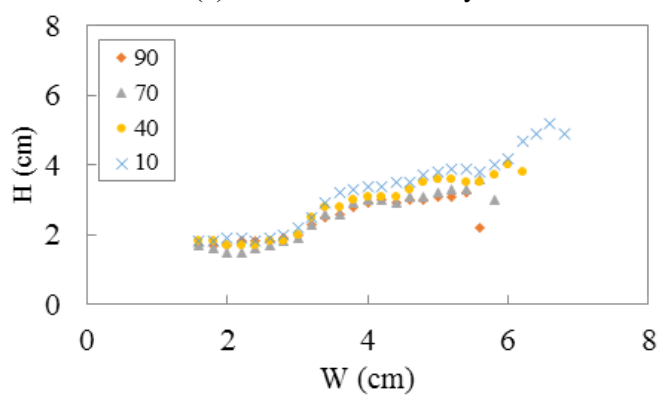

(b) Beads in loose array 


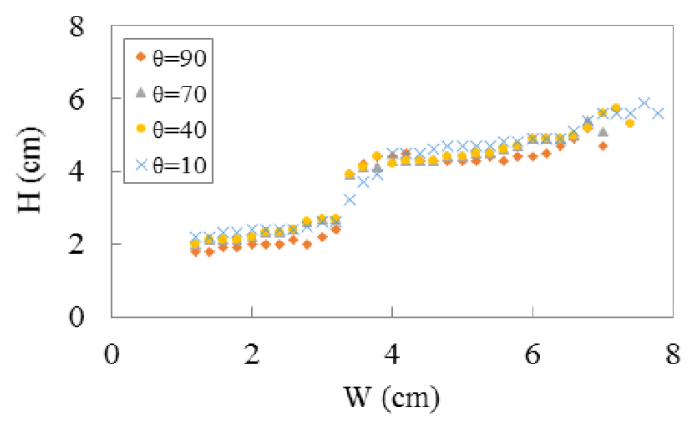

(c) Gravel

Fig. 6. Relation between door width (W) and arch height (H) for different base angles

The maximum door width $\left(\mathrm{W}_{\max }\right)$, which is the width of the door that no stable arch can form over the opening door with greater width, was measured by visual inspection. The $\mathrm{W}_{\max } / \mathrm{d}_{50}$ values versus different base angles for tested granular materials are presented in Fig. 7. As shown, the $W_{\max }$ varies from five times the average particle size $\left(\mathrm{d}_{50}\right)$ for loose beads on the base angle of $90^{\circ}$ to 8.6 times $\mathrm{d}_{50}$ for gravel on the base angle of $10^{\circ}$. Although there is a considerable debate on the maximum possible width of the outlet [23-27] in the literature, these observed data is comparable with experimental results obtained by Guo and Zhou [17] for granular materials e.g., glass beads (with $\mathrm{d}_{50}=5.5 \mathrm{~mm}$ ) and dense sand on the base angle of $30^{\circ}$.

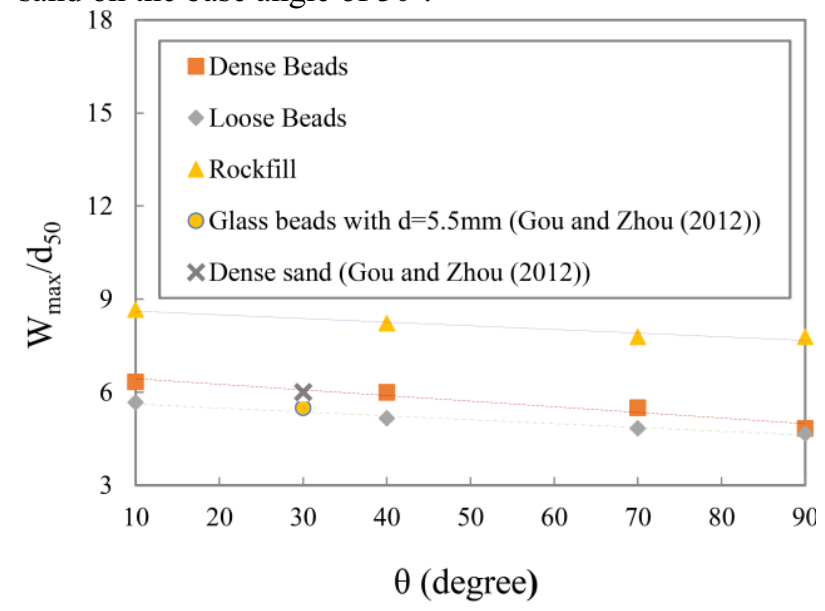

Fig. 7. Maximum opening door size versus different base angles

\section{Conclusion}

In this study, a developed trapdoor apparatus was implemented. An experimental analysis for ensembles of almost mono-sized particles of granular materials shows that stable arches may form with various widths depending on particle shape and the friction angle. For tested granular materials in this study, the critical width of opening door is approximately five to 8.6 times particle sizes. It is also observed that for all tested granular materials, an increase in door size and a decrease in base angle augment the width and height of the arch. However, on the verge of arch collapse, the height of critical arch decreases. This finding can be useful for granular flow in silos or hoppers.

\section{References}

1. K. Terzaghi, Theoretical soil mechanics: J. Wiley and Sons, Inc. (1943).

2. Y.-J. Jiang and I. Towhata, Rock Mechanics and Rock Engineering 1 (2012).

3. H. Akbarzadeh and A. Bayat, Tunn. Undergr. Sp. Tech. 39, 50 (2012).

4. C.N. Chen, W.-Y. Huang, and C.-T. Tseng, Tunn. Underg. Sp. Tech. 26, 228 (2011).

5. R.P. Chen, L.J. Tang, D.S. Ling, and Y.M. Chen, Comp. Geotech. 38, 187 (2011).

6. R.-P. Chen, J. Li, L.-g. Kong, and L.-j. Tang, Tunn. Underg. Sp. Tech. 33, 12 (2013).

7. C.J. Lee, B.R. Wu, H.T. Chen, and K.H. Chiang, Tunn. Underg. Sp. Tech. 21, 119 (2006).

8. M. Kahyaoglu, G. Imançli, O. Önal, and A. Kayalar, KSCE J. Civ. Eng. 16, 562 (2012).

9. S.J.M. Eekelen, A. Bezuijen, H.J. Lodder, and A.F. Van Tol, Geotext. Geomembr. 32, 69 (2012).

10. Y.S. Karinski, A.N. Dancygier, and I. Leviathan, Eng. Struc. 25, 91 (2003).

11. Miccio, Barletta, and Poletto, Powder Tech. 235, 312 (2013).

12. A.W. Roberts, Particuology 8, 591 (2010).

13. A. Garcimartín, I. Zuriguel, L. A. Pugnaloni, and A. Janda, Phys. Rev. E 82, 031306 (2010).

14. K. To and P.-Y. Lai, Phys. Rev. E 66, 011308 (2002).

15. H.-J. Tien "A Literature Study of the Arching Effect," SM, MIT (1996).

16. B. Chevalier, G. Combe, and P. Villard, 18ème Congrès Français de Mécanique, Grenoble, France (2007).

17. B. Chevalier, G. Combe, and P. Villard, Acta Geotechnica 7, 15 (2012).

18. A. Drescher, A.J. Waters, and C.A. Rhoades, Powder Tech. 84, 165 (1995).

19. Guo and Zhou, Int. J. Num. Analytical Methods In Geomechanics 37, 1048 (2012).

20. K.K. Rao and P.R. Nott, Cambridge University Press, 7 (2008).

21. K. To, P.-Y. Lai, and H. K. Pak, phys. Rev. Lett., $86,71(2001)$

22. I. Zuriguel, A. Garcimartín, D. Maza, L. A. Pugnaloni, and J. M. Pastor, Phys. Rev. E 71, 051303 (2005).

23. K. To, Phys. Rev. E 71, 060301-R (2005).

24. A. Janda, I. Zuriguel, A. Garcimartín, L. A. Pugnaloni, and D. Maza, Europhys. Lett. 84, 44002 (2008).

25. C. C. Thomas and D. J. Durian, Phys. Rev. Lett. 114, 178001 (2015).

26. R. Arévalo, I. Zuriguel, D. Maza, and A. Garcimartín, Phys. Rev. E 89, 042205 (2014).

27. R. Arévalo and I. Zuriguel, Soft Matter 12, 123 (2016) 